Z. Klin. Chem. Klin. Biochem.

11. Jg. 1973 , S. $393-397$

\title{
Thin Layer Chromatography of KREBS Cycle Acids
}

\author{
By H. P. KraIker and R. E. BurCH ${ }^{1}$ ) \\ From the Medical Service, Francis Delafield Hospital and The Department of Medicine, Columbia University \\ College of Physicians and Surgeons, New York, N. Y. 10032
}

(Eingegangen am 6. September 1972/3. Mai 1973)

\begin{abstract}
A systematic appraisal of a large number of solvent systems was carried out for the separation of lactic, pyruvic and 3-hydroxybutyric acids and all of the KREBS cycle acids, except oxalosuccinic, using silica gel $G$ and cellulose thin layer chromatographie plates. Four solvent systems which allowed separation of various combinations of acids are described and the limits of this method of separation are detailed.

Für die Trennung organischer Säuren wurde cine Wertung einet großen Zahl von Lösungsmittelsystemen durchgeführt. Untersucht wurde die dünnschichtchromatographische Trennung von Milch-, Brenztrauben- und 3-Hydroxybuttersäure sowie aller Säuren des Citronensäurezyklus außer Oxalbernsteinsäure an Silicagel-G- und Celluloseplatten. Vier Lösungsmittelsysteme, die die Trennung verschiedener Kombinationen dieser Säuren gestatten, werden mitgeteilt. Die Grenzen dieser Trennungsmethode werden eingehend diskutiert.
\end{abstract}

To our knowledge the only procedures which satisfactorily separate the KREBS cycle acids as well as some other acids of biological importance (lactic, pyruvic and $\beta$-hydroxybutyric acids) are column partition and ion exchange chromatography. The first method uses the principle of an inert support material and a gradient elution system of non-polar and polar solvents $(1,2)$. The latter procedure applies the principle of gradient elution in connection with an ion exchange resin $(3,4,5)$ (e. g. formic acid in increasing concentrations and the formate form of a Dowex-I column [3]). Column partition chromatography has been the basic principle of an organic acid autoanalyzer recently developed by KESNER and Muntwyler (6). Gas-liquid chromatography has also been used to separate weak organic acids $(7,8)$ but is still in the early stages of development.

Both in paper and thin-layer chromatography only a few reports have been published dealing. with the separation of non-amino organic acids, including a few belonging to the KreBs cycle as well as lactic, pyruvic and other acids. Whereas mixtures of an homologous series, e.g. the n-monocarboxylic acids (9), can be separated quite easily, the separation of complex mixtures of acids can hardly be expected to be complete. The difficulties of separation have been reflected in a series of papers by KaUFMANN and his co-workers $(10-15)$ who almost always achieved incomplete separation of complex acid mixtures of biological or industrial importance on silica-gel and alumina columns. Mixtures of saturated dicarboxylic acids $\left(\mathrm{C}_{2}-\mathrm{C}_{8}\right)$ including succinic acid have been satisfactorily separated on silicagel $G$ using benzene-methanol-glacial acetic acid and benzene-dioxane-glacial acetic acid as the solvent system by Petrowitz and Pastuska (16). Braun and Geenen achieved separation of the same acids on silica-gel $\mathrm{G}$ using a mixture of ethanol-ammonia- $\mathrm{H}_{2} \mathrm{O}$ (17). $P_{R E Y}$ et. al. separated formic, lactic and pyruvic acids
(18); Pastuska and Petrowitz (19) separated the cis-trans isomers of maleic, crotonic, iso-crotonic, tiglic, citraconic, mesaconic, itaconic, and aconitic acids. It is noteworthy that the trans forms of these acids migrated faster than the cis forms.

Since thin layer chromatography is fast and inexpensive and has not been used extensively as a means of separating KREBS cycle acids, we compared a wide spectrum of thin layer systems and evaluated their efficacy in separating lactic, pyruvic, $\beta$-hydroxybutyric and the KREBS cycle acids. As will be seen below some of these methods are sensitive enough for many investigational purposes in which only a limited number of acids might be of interest.

\section{Methods and Materials}

(1) Pre-coated plates, $20 \times 20 \mathrm{~cm}$ in size, were purchased from E. Merck, Darmstadt, Germany (distributed by Brinkmann Instruments, Inc. in the U. S.). The types used were Silica Gel G (7731) and Silica Gel GF-254 (7730), and Cellulose and Cellulose F.

(2) DL-malic, DL-lactic, DL-iso-citric, succinic, pyruvic, cis-aconitic and fumaric acids were purchased from Sigma Chemical Company, St. Louis, Missouri. Citric, 2-oxoglutaric and oxaloacetic acids were obtained from Calbiochem, Los Angeles, California, and 3-hydroxybutyric acid from Mann Research Laboratory, New York, N. Y. Standard solutions were prepared by dissolving $100 \mathrm{mg}$ of each acid except fumaric in $4 \mathrm{ml}$ of acetone-water (1:1). Fumaric acid was dissolved in ethanol. Spotting was done with micro. pipettes.

(3) BRINKMANN tanks were lined with filter paper and equilibrated overnight, except in a few instances where they were equilibrated for at least 6 hours. The room temperature was $23 \pm 2^{\circ} \mathrm{C}$. For orientation the solvent was allowed to run at least $10 \mathrm{~cm}$. To check reproducibility in promising solvents the development was interrupted after a pre-marked $15 \mathrm{~cm}$ line was reached. The plates were air-dried overnight or heated for $30-45 \mathrm{~min}$ at $110^{\circ} \mathrm{C}$. (particularly when the solvent contained acetic or formic acid).

1) Supported by Grants HE-00052 from the National Institutes of Health and U-1562 from The Health Research Council of the City of New York. 
(4) Spots were visualized by:

a) spraying with bromocresolgreen (22) $(0.04 \mathrm{gm}$ of bromocresolgrcen in $100 \mathrm{ml} 96 \%$ cthanol adjusted with $0.1 \mathrm{~mol} / 1 \mathrm{NaOH}$ until blue coloration just appears);

b) by inserting the plate into a tank with iodine vapor; or

c) with potassium permanganate spray reagent (22) (0.5 g of $\mathrm{KMnO}_{4}$ very cautiously dissolved in $15 \mathrm{ml}$ of concentrated sulfuric acid). Depending on the sorbent/solvent combination used it was necessary in some instances to re-heat the plates for a few minutes after spraying with bromocresol-green. To check detection by fluorescence the indicator-containing plates were used (types GF-254 and Cellulose F); the regular plates were sprayed, after development with the solvent, with a rhodamine spray $(2 \mathrm{ml}$ of $0.5 \%$ rhodamine in methanol solution $+100 \mathrm{ml}$ of $2 \mathrm{~mol} / \mathrm{l}$ $\mathrm{NH}_{4} \mathrm{OH}$ ).

\section{Results}

\section{Sorbents and solvents}

Initially, separation of all the KREBS cycle acids except oxalosuccinic (extremely unstable) plus lactic, pyruvic and 3-hydroxybutyric acids was tried on silica gel $G$ with solvent systems reported by different authors:

Methanol: $5 \mathrm{~mol} / 1$ Ammonia (80 ml $+20 \mathrm{ml}$ ) (20)

96\% Ethanol: $\mathrm{H}_{2} \mathrm{O}: 25 \%$ Ammonia (100 ml $+12 \mathrm{ml}$ $+16 \mathrm{ml})(17)$

Benzene: Methanol: Acetic acid $(90 \mathrm{ml}+16 \mathrm{ml}+$ $8 \mathrm{ml})(16)$

Benzene: Dioxane: Acetic acid $(90 \mathrm{ml}+25 \mathrm{ml}+$ $4 \mathrm{ml})(16)$

Only succinic and citric acid could be separated (citric acid tailed in each system) and they always had highly different $R_{\mathrm{F}}$ values. Empirically, the combination of ethanol-ammonia was most promising. By gradually increasing the volume percentage of ammonia the optimal ratio was found to be 65 ( $96 \%$ ethanol) to 35 (conc. ammonia) with no additional water added. This combination turned out to be even better suited for cellulose layers with regard to sensitivity and sharpness of spots.
On both silica gel $G$ and cellulose, however, separation was incomplete (Column I in Table 1 and 2).

Because of the incomplete separation obtained with the solvent systems above, a systematic evaluation of a large number of solvent systems was undertaken. Again, highly "active" silica gel G layers were used as well as comparatively "inactive" cellulose layers. With $25 \mu \mathrm{g}$ of each acid spotted, the following common pure solvents were evaluated in accordance with their dielectric constants :

$n$-hexane (1.9), petroleum ether (2.0), cyclohexane (2.0), carbon tetrachloride (2.2), benzene (2.3), toluene (2.4), diethyl ether (4.3), chloroform (4.8), ethyl acetate (6.0), butanol (17.8), iso-propanol (18.3), n-propanol (20.3), acetone (20.7), ethanol (24.3), methanol (32.6) and water (78.5).

In regard to dielectric constants the suitable range proved to be from butanol (17.8) to ethanol (24.3). With solvents more polar than ethanol the acids migrated with or very close to the solvent front. With solvents less polar than butanol the samples remained at or close to the origin. The only unexplained exceptions to this general observation, confirmed by the circular technique $(21,22)$, were benzene and methylbenzene (toluene). Both led to promising separation of the acids but streaking and tailing could not be eliminated by varying the $\mathrm{pH}$ from 2 to 10 (adjusted with acetic acid, formic acid or ammonia). With diethyl ether as the solvent the acids could not be detected, most probably because of the fact that all of them - though to a different degree are soluble in ether and diffuse into the plate. Ethanol, also a good solvent for most of the acids, has a much higher dielectric constant and does not lead to diffusion of the samples into the layer.

To suppress streaks and tails $n$-butanol, iso-propanol, $n$-propanol, acetone and ethanol were subjected to

Tab. 1

$R_{F}$ values of KREBS cycle acids chromatographed on silica gel $G$ thin layer plates with various solverit systems Solvent system 1 . Separates acids with high $R_{F}$ values (3-hydroxybutyric, lactic, fumaric and 2-oxoglutaric acids) from acids with lower $R_{F}$ values (malic, succinic and citric plus iso-citric acids). 3-Hydroxybutyric acid can be distinguished from 2-oxoglutaric if these acids are present in amounts smaller than about $150 \mu \mathrm{g}$. - Solvent system II. Separates lactic and 3-hydroxybutyric acids from fumaric and citric acids. If 2-oxoglutaric acid is present it will overlap with cis-aconitic and fumaric acids. - Solvent system III. Separates succinic from citric, fumaric and malic acids. If cis-aconitic acid is present it will overlap with fumaric and malic acids. - Solvent system IV. Separates lactic and 3-hydroxybutyric acids from citric plus cis-aconitic acids. Fumaric, 2-oxoglutaric, malic and succinic acids stay close to the origin and, if present, interfere with citric plus cis-aconitic acids

\begin{tabular}{|c|c|c|c|c|}
\hline Solvent system* & I & II & III & IV \\
\hline cis-Aconitic & 0.13 (yellow) & close to origin & 0.40 (yellow) & close to origin \\
\hline Citric & 0.12 (yellow) & origin (yellow) & 0.14 (yellow) & origin (yellow) \\
\hline DL-iso-Citric & origin; hard to detect & not detected & not detected & not detected \\
\hline Fumaric & 0.61 (yellow) & 0.14 (yellow) & 0.42 (yellow) & 0.14 (yellow) \\
\hline DL-3-Hydroxy-butyric & 0.70 (yellow) & 0.29 (yellow) & not detected & 0.27 (yellow)** \\
\hline 2-Oxoglutaric & 0.58 (yellow) & 0.1 (yellow) & $\begin{array}{l}0.36 \text { (brown; } \\
\text { iodine vapor) }\end{array}$ & 0.12 (yellow) \\
\hline DL-Lactic & 0.62 (yellow) & 0.31 (yellow) & not detected & 0.23 (yellow)** origin (blue) \\
\hline DL-Malic & 0.32 (yellow) & close to origin & 0.32 (yellow) & close to origin \\
\hline Oxaloacetate & $\begin{array}{l}\text { origin (yellow) } \\
\text { streak (iodine vapor) }\end{array}$ & close to origin & $\begin{array}{l}0.42 \text { (brown; } \\
0.18 \text { iodine vapor) }\end{array}$ & streak (iodine vapor) \\
\hline Pyruvic & origin (blue) & not detected & $\begin{array}{l}0.41 \text { (brown; } \\
\text { iodine vapor) }\end{array}$ & $\begin{array}{c}\text { streak (iodine vapor) } \\
0\end{array}$ \\
\hline Succinic & 0.46 (yellow) & close to origin & 0.58 (yellow) & 0.10 (yellow) \\
\hline
\end{tabular}

* The Roman numerals correspond to the solvent systems described in the text.

** Detected only with $100 \mu \mathrm{g}$ spotted. 
Tab. 2

$R_{F}$ values of KREBS cycle acids chromatographed on cellulose thin layer plates with various solvent systems Solvent system I. Separates lactic and 3-hydroxybutyric from either fumaric, 2-oxoglutaric, malic or succinic acids. All of these acids can be distinguished from citric acid. Cis-Aconitic acid will overlap with citric acid. - Solvent system II. Separates lactic acid and 3-hydroxybutyric acid from either citric, cis-aconitic, fumaric, 2-oxoglutaric, malic or succinic acids (the latter group stays at or very close to the origin). - Solve $\mathrm{n}$ system 111. Separates fumaric, lactic, 3-hydroxybutyric and succinic acids as a group from either citric plus cis-aconitic or malic acids. It could not be decided whether the different spots obtained in this system with cis-aconitic and citric acids do contain citric and cis-aconitic acids. The different spots may represent different ionic species or isomers. However, with a view to the other systems checked, it is likely that the higher $R_{F}$ values indicate cis-aconitic acid. - Solvent system IV. Separates lactic and 3-hydroxybutyric from citric acid. cis-Aconitic, fumaric and 2-oxoglutaric acids, if present, overlap with citric acid

\begin{tabular}{|c|c|c|c|c|}
\hline Solvent system* & I & II & III & IV \\
\hline cis-Aconitic** & $\begin{array}{l}0.35 \text { (yellow) } \\
0.48 \text { (yellow; trans) }\end{array}$ & close to origin (yellow) & $\begin{array}{l}0.53 \text { (yellow) } \\
0.42 \text { (yellow) } \\
0.28 \text { (blue) } \\
0.70 \text { (yellow; trans?) }\end{array}$ & close to origin \\
\hline Citric** & 0.27 (yellow) & origin (yellow) & $\begin{array}{l}0.54 \text { (yellow) } \\
0.43 \text { (yellow) } \\
0.28 \text { (blue) }\end{array}$ & close to origin \\
\hline DL-iso-Citric** & 0.23 (blue) & close to origin (blue) & 0.31 (blue) & 0.10 (blue) \\
\hline Fumaric & 0.56 (yellow) & close to origin (yellow) & 0.79 (yellow) & 0.17 (yellow) \\
\hline DL-3-Hydroxy-butyric & 0.72 (yellow) & 0.37 (yellow) & 0.77 (yellow) & 0.35 (yellow) \\
\hline 2-Oxoglutaric & $\begin{array}{l}0.33 \text { (Dlue) } \\
0.52 \text { (yellow) }\end{array}$ & $\begin{array}{l}0.18 \text { (blue) } \\
\text { close to origin (yellow) }\end{array}$ & $\begin{array}{l}0.31 \text { (blue) } \\
0.58 \text { (yellow) }\end{array}$ & $\begin{array}{l}0.15 \text { (blue) } \\
0.16 \text { (yellow) }\end{array}$ \\
\hline DL-Lactic & 0.72 (yellow) & 0.37 (yellow) & 0.74 (yellow) & 0.35 (yellow) \\
\hline & 0.48 (blue) & 0.22 (blue) & 0.41 (blue) & 0.22 (blue) \\
\hline DL-Malic & 0.47 (yellow) & close to origin (yellow) & 0.55 (yellow) & 0.12 (yellow) \\
\hline Oxaloacetic & $\begin{array}{l}0.46 \text { (yellow) } \\
\text { poorly reproducible }\end{array}$ & not detected & $\begin{array}{l}0.56 \text { (yellow) } \\
\text { poorly reproducible }\end{array}$ & close to origin \\
\hline Pyruvic & 0.26 (blue) & close to origin (blue) & $\begin{array}{l}0.53 \text { (yeliow) } \\
\text { poorly reproducible } \\
0.31 \text { (blue) }\end{array}$ & close to origin \\
\hline Succinic & 0.61 (yellow) & close to origin (yellow) & 0.78 (yellow) & 0.14 (yellow) \\
\hline
\end{tabular}

* The Roman numerals correspond to the solvent systems described in the text.

** See last paragraph on this page.

slight-to-strong acidification (with increasing concentrations of acetic or formic acid) as well as alkalinization (using ammonia). n-Butanol and acetone gave the best results when mixed and acidified. The same mixture plus ammonia (ammonium acetate is formed in a highly exothermic reaction) was succesfully used for fractionating nucleotides on cellulose layers by RANDERATH (23). This system failed to yield reproducible separations with the acids investigated in this study. The $n$-propanol system (see II below) proved to be suited for the separation of lactic, fumaric and citric acids. The majority of the acids do not leave the origin. iso-Propanol was not superior to n-propanol.

In summary, four solvent systems were checked for consistency of results. Reproducibility was assumed when, in at least 6 runs, the $R_{\mathrm{F}}$ values did not deviate more than \pm 0.03 . Greater variations were observed with inconstant length of run. We have also observed that $R_{\mathrm{F}}$ values increase slightly when smaller amounts of samples are spotted. This observation has also been noted by other authors (17).

The $R_{\mathrm{F}}$ values using these systems are shown in Tables 1 and 2 where the solvents used are designated as follows

I $96 \%$ Ethanol:Ammonia (65 ml $+35 \mathrm{ml})$

II n-Propanol:Ammonia: $\mathrm{H}_{2} \mathrm{O}(80 \mathrm{ml}+10 \mathrm{ml}+$ $10 \mathrm{ml}$ )

III n-Butanol:Acetone:Ammonia: $\mathrm{H}_{2} \mathrm{O}(35 \mathrm{ml}+$ $25 \mathrm{ml}+15 \mathrm{ml}+10 \mathrm{ml})$

IV $n$-Butanol:Acetone: Acetic Acid: $\mathrm{H}_{2} \mathrm{O}(35 \mathrm{ml}+$ $25 \mathrm{ml}+15 \mathrm{ml}+10 \mathrm{ml})$

\section{Detection}

After spraying with bromocresol-green the spots have to be outlined with a sharp pencil immediately since color changes take place within a few hours. Decomposed - e. g. overheated - acids do not react with bromocresol green. Their organic remnants can be detected with iodine vapor or potassium permanganate spray. Generally, for equal amounts of different substances, the intensity of the color and the size of the spot are known to decrease with increasing chain length (22). This does not simplify the identification of spots because the acids investigated cover a wide range of $R_{\mathrm{F}}$ values. With increasing $R_{\mathrm{F}}$ value (or lenght of run), in turn, the spot areas increase as well, and thus, the intensity of the color produced by the indicator is diminished. The theoretical aspects of the relationship between length of run and spot area have been discussed by BRIMLEY (24). Decomposition is most likely with oxaloacetic and pyruvic acids. The first one, being a 3-oxocarboxylic acid, decarboxylates spontaneously in aqueous solutions, especially in an acid medium. Pyruvate, as the decarboxylation product, never reproducibly gave a yellow spot with bromocresol green. Presumably oxidative fission into $\mathrm{CO}_{2}$ and acetaldehyde took place.

Citric acid in all solvent systems stays at, or close to, the origin. iso-Citric acid was not detected on silica gel $G$ and gave blue spots on cellulose. ENGLARD and Colowrck (25) have studied the equilibrium of citric and iso-citric acids and the common anhydride (cisaconitic acid) as well as the kinetics of cis-aconitase and 
iso-citric dehydrogenase. Since in this equilibrium citric acid is the strongest and most stable compound it is not surprising that it appears as a bright yellow spot. If a large amount of cis-aconitic acid $(150 \mu \mathrm{g})$ was spotted on cellulose and run in solvent system III an additional yellow spot with the $R_{\mathrm{F}}$ value of citric acid was observed as well as a blue spot close to the origin. This blue spot probably represents decomposed iso-citric acid. If $c i s$-aconitic acid was spotted in large amounts $(150 \mu \mathrm{g})$ on cellulose and run in solvent system I, an additional yellow spot with an $R_{\mathrm{F}}$ higher than citric acid was observed. It is likely that this spot represents formation of some trans-aconitic acid (the commercial acid used in this study was trans-isomer free) since the trans forms are known to migrate faster (19), although this was not proven by elution and enzymatic determination. On cellulose the yellow spots of lactic and 3-hydroxybutyric acids had almost identical $R_{\mathrm{F}}$ values and were followed by blue spots which had $R_{\mathrm{F}}$ values different from each other.

Detectability by fluorescence was not superior to bromocresol green in terms of sensitivity. Further, bromocresol green is more specific for organic acids.

\section{Sensitivity}

Lactic, malic, fumaric, succinic, 2-oxoglutaric, citric and cis-aconitic acids could be visualized with $6 \mu \mathrm{g}$ spotted on silica gel $\mathrm{G}$. When sprayed with bromocresol green, equal amounts of a given acid gave a considerably brighter stain on cellulose than on silica gel plates. 3-Hydroxybutyric acid on both types of plates could only be visualized in quantities of at least $25 \mu \mathrm{g}$. With pyruvic, oxaloacetic and iso-citric acids or their decomposition products, respectively, detectability varies widely with such factors as the age of the standard solutions and whether or not the plates were heated. Generally, with these unstable acids detectability was poor.

\section{Quantitative estimation}

Theoretically, as was shown by GIDDINGs and KELLER (26), the density of the chromatographed substance along the axes $x$ and $y$ of the spot follows a Gaussian distribution. Fisher et al. $(27,28)$ have shown that the area of the spot increases as the logarithm of the spot content. This finding indicates that exact linearity between the spot content and the area cannot be assumed. However, planimetric measurements has been done by several authors with considerable accuracy $(28,29)$. Counting the area of spots in $\mathrm{mm}^{2}$ we found an almost linear relationship between the area of the spot and the amount of the applied acid in the range of 10 to $100 \mu \mathrm{g}$.

\section{Two-dimensional separation}

Two-dimensional separation, using a combination of solvent systems I-IV, is unsatisfactory for several reasons. First, acids having a high $R_{F}$ value in one system behave similarly in other systems as well (Tables 1 and 2). Second, the spot area increases with the extended lenght of run in the second dimension (24) thus hampering the detection limit.

However, by using system III in the first, and system I in the second dimension on cellulose a better separation of some of the acids is obtained than in a unidimensional system, provided a minimal amount of acid is present for detection. This depends on the individual acid and generally is about 40 to $70 \mu \mathrm{g}$. With large amounts $(200 \mu \mathrm{g})$ succinic and fumaric, 3-hydroxybutyric and lactic as well as 2-oxoglutaric and malic acids will partially overlap. To avoid elution and enzymatic identification procedures, 11 plates were run under identical conditions. At the origin a mixture containing $75 \mu \mathrm{g}$ of each acid was spotted on all plates. To assure an excess of one of the eleven standard acids on each plate (for purposes of identification) an additional $75 \mu \mathrm{g}$ of the standard acid which was to be added in excess was spotted at the origin. Thus, each plate contained $75 \mu \mathrm{g}$ of 10 standard acids and $150 \mu \mathrm{g}$ of the individual standard which was to be present in excess. Lactic (tailing), 3-hydroxybutyric, fumaric, succinic, malic and citric acids could be located by this procedure. 2-Oxoglutaric acid after the second-dimension could only be visualized with iodine vapor and did not have the $R_{F}$ values expected from the unidimensional runs. Theoretically, the spots of 2-oxoglutaric, oxaloacetic and malic acids are overlapping. In practice, the first two decompose and only malic acid will be visualized with bromocresol green. Citric acid theoretically interferes with the blurred blue spot of pyruvate. The latter could not be visualized in the citric acid area. cis-Aconitic acid was not detected after the second-dimension run. A large blue spot in the lower left quadrant of the plate probably corresponds to a mixture of decomposition products of iso-citric, 3-hydroxybutyric and pyruvic acids.

\section{Discussion}

Theoretically, heterogenous acids such as the ones studied could not be expected to be easily separated by standardized thin layer chromatography procedures. Since they do not represent a particular structural group (e. g. 2-oxo-acids, 3-hydroxy-acids, aliphatic series etc.) separation depends on the respective molecule structure as related to given sorbent/solvent-systems. Acids forming a biological cycle, such as the Kreiss-cycle, are highly different with regard to their physico-chemical properties, particularly their oxidation state, tendency towards isomerization, $\mathrm{pH}$-dependency and heat stability.

Thus, this article must be understood as an empirical approach to an optimal separation with solvents of gradually increasing dielectric constants. This is one principle out of other possible guidelines which could have been applied (e. g. checking a large number of coating materials). As a general rule, this article confirms that when biological materials are to be studied by thin layer chromatography, the suitable separation procedure de- 
pends largely on which substances can be expected, or which predominate from a "clinical" point of view. Thin layer chromatography will hardly be satisfactory for the complete analysis fo biological samples, either qualitatively or quantitatively, since biological materials in general contain too many known and unknown heterogenous compounds. Pilot studies will have to decide whether relatively inexpensive thin layer chromatography will suit a given problem.

The study of more recent thin layer chromatography literature reveals, consequently, that the thin layer chromatography-analysis of biological material is most often restricted to certain structurally related compounds, particularly those differing only in chain length. The 2-oxo-carbonic acids of urine have been separated in vitro by BAYZER (30) and by LUTZ and v. REUTERN (31) with particular regard to phenylketonuria and cystinuria, as well as by StAN and SCHORMÜLLER (32). RüDIGER, Nikisch and Goedde (33) and Trop, GrosmanN and PINSKY (34) applied special procedures to distinguish 2-oxo- und 3-hydroxy-acids. Chan, Chang and STOFFORD (35) published a remarkable study on thin layer chromatography separation of non-volatile biological acids (out of papaya fruit material). CHuRACEK
(36) has published new thin layer chromatographyreagents for the identification of acids, alcohols and amino-compounds both in vitro and in biological material.

Thома (37) has described a method for predicting the chromatographic behaviour of a third solvent from chromatographic data of another two. Planimetric, photometric or surface significance was studied by KLAUS (38), KLoubek (39) and KöhleR (40). More recently, StaN and SCHORMüLLER (32) published a method for quantitative determination after elution, whereas RÜDIGER et al. introduced isotope techniques to separate compounds of close or overlapping $R_{\mathrm{p}}$-values (33).

Studies such as the ones indicated confirm that the thin layer chromatography separation of biological materials can be predicted only to a certain degree, since too many parameters are usually involved. For a given problem, therefore, empirical studies must be carried out since theoretical prediction is limited.

Recent papers underline the fact that thin layer chromatography-procedures must be worked out to suit a given problem or modified whenever a standardized procedure is applied to separate biological material other than the one the original method was designed for.

\section{References}

1. KesNer, L. \& Muntwyler, E. (1963), J. Lab. Clin. Med. 61, 604-619. - 2. SwIM, H. E. \& UTTER, M. F. (1957), Methods Enzymol. 4, 584 -609. - 3. Busch, H., Hurlbert, R. B. \& PotTER, V. R. (1952), J. Biol. Chem. 198, 71-77. - 4. Owens, H. S., Goodhan, A. E. \& Stark, J. B. (1953), Anal. Chem. 25, 1507 -1511. - 5. Schenker, H. H. \& RiemanN, W. (1953), Anal. Chem. 25, 1637-1641. - 6. KESNER, L. \& MUNTwYLER, E. (1966), Anal. Chem. 38, 1164 -1168. - 7. Alcock, N. W. (1965), Anal. Biochem. 11, 335-343. - 8. GeE, M. (1965), Anal. Chem. 37, 926-934. - 9. Hromatka, O. \& Aue, W. A. (1963), Mh. Chemie 93, 503-512. - 10. KaufmanN, H. P. (1939), Fette, Seifen, Anstrichmit. 46, 268-274. - 11. KaufmanN, H. P. (1940), Fette, Seifen, Anstrichmit. 47, 460-473. - 12. KaufmanN, H. P. (1940), Angew. Chem. 53, 98-99. Int. Ed. Engl. - 13. KaufmanN, H. P. \& KIrSCh, P. (1943), Fette, Seifen, Anstrichmit. 50, 519-524. - 14. Kaummann, H. P. \& Schmidt, O. (1940), Fette, Seifen, Anstrichmit. 47, $294-305$. - 15. KaurmanN, H. P. \& Wolf, W. (1943), Fette, Seifen, Anstrichmit. 50, 519-527. 16. Petrowitz, H. J. \& Pastuska, G. (1962), J. Chromatogr. 7, 128-130. - 17. Braun, D. \& Geenen, B. (1962), J. Chromatogr. 7, 56-59. - 18. Prex, V., Berbalk, H. \& Kausz, M. (1962), Mikrochim. Acta, 449-461. - 19. Pastuska, G. \& Petrowrrz, H. J. (1963), J. Chromatogr. 10, 517-518. - 20. WALDr, D., unpublished, quoted after Stahl (22), 1st ed., p. 357. - 21. Iz- mailow, H. \& Schraiber, S. (1938), Fatmazia 3, 1-7. - 22. StAHL, E. (1972), Thin Layer Chromatography, 2nd ed., Springer Verlag, Berlin-Heidclberg-New York. - 23. Randerath, K. (1962), Nature (London) 194, 768-769. - 24. BRIMLEY, R. C. (1949), Nature (London) 163, 215-216. - 25. ENGLARD, S. \& Colowick, S. P. (1957), J. Biol. Chem., 226, 1047-1058. 26. Giddings, J. C. \& Keller, R. A. (1959), J. Chromatogr. 2, 626-633. - 27. Fisher, R. B. \& Holmes, R. (1949), Biochemistry 44 , liv. - 28. Fisher, R. B., Pearsons, D. S. \& Morrison, G. A. (1948), Nature (London) 161, 764-765. - 29. REID, R. L. \& LeDERER, M. (1951), Biochem. J., 50, 60-73. - 30. BAYZER, H. (1971), J. Chromatogr. 57, 281-286. - 31. LUTZ, P. \& v. REUTERN, G. M. (1969), this j. 7, 586-589. - 32. STAN, H. J. \& SCHORMüLLER, J. (1969), J. Chromatogr. 43, 103-109. - 33. Rüdiger, H. W., NikisCh, M. \& Goedde, H. W. (1971), J. Chromatogr. 61, 373-375. - 34. Trop, M., Grossmann, S. \& Pinsky, A. (1968), J. Chromatogr. 38, 411-413. - 35. ChAn, H. T., Chang, T. S., Stofrord, A. E. \& Brekke, J. E. (1971), J. Agr. Food Chem. 19, 263-265. - 36. ChuraceK, J. (1970), J. Chromatogr. 48, 241-249. - 37. Тнома, J. A. (1965), Anal. Chem. 37, 500-508. - 38. Klaus, R. (1967), Pharm. Ztg., 2. Mitteilung 112, 480-484. - 39. KLoubex, J. (1965), Chemistry 37, 500-509. - 40. KöhLER, F. (1972), J. Chromatogr. 68, 275-279.

Dr. H. P. Kraiker Bundesknappschaft Klinik 6603 Sulzbach/Saar 